\title{
EL MUEBLE ESPAÑOL ENTRE ESPAÑA Y AMÉRICA DURANTE LA PRIMERA MITAD DEL SIGLO XX: CAMINOS DE «IDA Y VUELTA»
}

\author{
SPANISH FURNITURE PIECES BETWEEN SPAIN AND AMERICA DURING THE \\ FIRST HALF OF THE 20TH CENTURY: ROUND-TRIP PATHS
}

Javier Pérez-Flecha González*

Universidad Complutense de Madrid

\section{Resumen}

Se estudia en este artículo las razones y vías por las que el mueble español fue exportado y subastado en Nueva York para los coleccionistas y galerías que cumplían esta demanda y se dan ejemplos de ventas propiciadas por la galería French \& Co. Además, se analiza el retorno del mercado del anticuariado español tras la guerra civil y la importancia que tuvo en ello el mueble importado de vuelta a España desde Estados Unidos.

Palabras Clave: mueble, mobiliario, artes decorativas, comercio, galerías, French \& Co

\section{Abstract}

We study the reasons and paths why Spanish furniture were sent and auctioned at New York for the galleries and collectors who requested this kind of artworks, giving examples of sales made possible by the French \& Co gallery. Moreover, we analize the return of the Spanish antiquarian market after the Spanish civil war and the importance that has the furniture exported back from the US on that reestablishment.

Key Words: decorative arts, furniture, antiquarian, galleries, French \& Co, exports

Fuera de toda duda queda, a día de hoy, que el uso del mueble en sus diferentes tipologías ha ayudado a la comodidad y confort en la vida doméstica de aquellas personas que lo han ido atesorando a lo largo de los siglos ${ }^{1}$, y para hacer de esa necesidad virtud, los diferentes estilos del mueble español han ido al corriente de las modas, siendo por tanto su presencia en el mercado de compraventa de arte y antigüedades, más que una constante.

"El presente artículo se enmarca dentro de mi tesis doctoral sobre el marchante y coleccionista de antigüedades José Weissberger (1878-1954), financiada conjuntamente por la Universidad Complutense y el Banco Santander mediante la convocatoria de ayudas para contratos pre doctorales de personal investigador en formación CT27/16-CT28/16. Deseo agradecer las anotaciones al texto de la Dra. Cruz Yabar". 
Fruto de ello y a tenor de los incipientes estudios que se dieron sobre su historia y procedencia a finales del siglo XIX y en la primera mitad del siglo $\mathrm{XX}^{2}$, el mueble español se revalorizó durante este tiempo en toda la Península Ibérica, como así mismo ocurrió con otras artes que denominamos, comúnmente, decorativas. El coleccionismo de mobiliario español, por causa de unas circunstancias concretas que luego veremos, no se quedó en nuestro país sino que dio el salto a América del Norte donde -sobre todo a partir de 1920 y del Spanish Colonial Revival Style- la exportación, venta y acumulación de estas piezas vivieron un auge sin precedentes entre los grandes magnates y coleccionistas del cambio de siglo, lo que además ayudó a su difusión como objeto funcional y lujoso o evocador de un pasado, y también a la de otras artes suntuarias y al conocimiento de la historia y la cultura artística españolas entre los sectores académicos de los Estados Unidos.

El viaje al otro lado del Atlántico de todo tipo de antigüedades -muebles incluidos- se vio frustrado más tarde y de manera estrepitosa por la Guerra Civil; las consecuencias del conflicto bélico también se hicieron notar en la disponibilidad que de estos ejemplares tenía el mercado de artes decorativas. De nuevo fueron los intercambios con América los que poco a poco fueron reconstruyendo el stock de las casas de antigüedades y reactivando el mercado, pero esta vez las piezas realizaban un camino de vuelta, de regreso, donde el mueble español recomprado en las galerías de Nueva York será una de las claves del interés de coleccionistas tanto nacionales como extranjeros en territorio peninsular.

\section{Caminos de ida: la exportación y venta del mueble español en América}

El coleccionismo de artes decorativas y antigüedades en la España de la primera mitad del siglo XX no fue un fenómeno nuevo, sino que como cabría esperar, basa sus precedentes en el siglo anterior. Las sucesivas desamortizaciones $^{3}$, pero sobre todo la eclesiástica, promovida por Juan Álvarez Mendizábal en 1836, puso en el mercado una ingente cantidad de obras de arte que los nuevos coleccionistas de corte burgués -nacidos al calor de la creciente industrialización de España- supieron aprovechar de manera eficiente. Se hicieron así con piezas de los siglos precedentes y procedentes de las iglesias desamortizadas. Ni que decir tiene que hubo una continuidad en los hechos durante la primera mitad del siglo XX, y si a finales del siglo XIX destacaron nombres como los marqueses de Salamanca y de Manzanedo o Pablo Bosch y Barrau ${ }^{4}$, en el XX sobresalieron entre los principales coleccionistas el marqués de Cerralbo, los condes de Valencia de Don Juan y de las Almenas, Félix Boix, Lafora, García Palencia, Luis Plandiura o las familias de los Ruiz, Byne o Weissberger.

Si en ambos siglos las obras de arte adquiridas y sobre todo los muebles servían -además de para el coleccionismo- para la adecuación de la vida doméstica, en el siglo XX se va a introducir un nuevo factor diferencial: su mercadeo por parte de los propios coleccionistas. Los establecimientos dedicados a la compraventa de antigüedades se multiplicaron de forma exponencial y, situados en los centros neurálgicos de las grandes ciudades -en Madrid estaban en la zona de las Cortes y del Rastro y en Barcelona en el entorno de la catedral ${ }^{5}$-, el negocio fue muy bien aprovechado por aquellos, pues de todas las piezas que 
adquirían, unas iban dirigidas a sus propias colecciones y el resto era mostrado y puesto a la venta en la tienda como indicaba el coleccionista Frederic Marés en sus memorias. ${ }^{6}$

Nacía así la dicotomía entre coleccionista y comerciante/marchante que aunaba ambas figuras en una sola persona. De esta forma, el negocio y la rentabilidad económica estaban más que asegurados, si bien hay que decir que esto fue posible debido a la gran cantidad de piezas de artes suntuarias y antigüedades puestas en circulación y a la alta demanda que había de ellas. Eran algunas veces los tratantes de arte -personajes relegados a un segundo plano-, pero en otras ocasiones los propios coleccionistas y galeristas o incluso incipientes historiadores del arte ${ }^{7}$, los que no dudaban en realizar expediciones a los lugares más recónditos de la geografía española y a sus iglesias y monasterios en busca de obras de arte que adquirir para el mercado. Muchas veces se hacían con aquellas que se habían relegado a un rincón, pues se les había dejado de dar uso; en otras ocasiones intentaban comprar las piezas históricas a las autoridades eclesiásticas entregándoles a cambio objetos nuevos y más modernos en estilo, que éstas aceptaban por ignorancia del valor histórico o artístico que tenía aquello de lo que se desprendían. De esta manera se colocaron en el mercado grandes conjuntos de sillas y sillones fraileros, sitiales, sillerías de coro, grandes mesas monásticas, escritorios o incluso hasta alguna puerta de entrada, además de otros muchos objetos fuera de la rama del mobiliario.

Esta práctica, muy cercana al «trapicheo», era la habitual y de la que ha quedado alguna documentación al respecto. ${ }^{8}$ Pero era, además, y por desgracia, el método más rápido y eficaz para que los centros religiosos se pudieran proveer de dinero líquido o de objetos necesarios para el culto, especialmente tras el desastre que había supuesto para ellos la desamortización.

Para el mercado de las casas de antigüedades y, por ende, para los coleccionistas españoles, se adquirían las piezas que estos últimos demandaban. Las fotografías de muchos interiores históricos, como luego veremos, nos demuestran que esta demanda se basó principalmente en las producciones españolas, y así hubo un afán generalizado por hacerse con toda suerte de antigüedades procedentes de nuestro propio país. Este gusto por lo español no sólo se debía, como hemos dicho, a la facilidad de acceso y compra de este tipo de piezas -que fomentaba a su vez el mercado-, sino que también estuvo en cierta manera influido por las corrientes regeneracionistas de renovación del país. Desde finales del siglo XIX, y por los hechos históricos acontecidos, se hizo patente desde el intelectualismo burgués otra forma de mirar y estudiar la historia y sus producciones artísticas, y ello llevó a reconsiderar y admirar las artes suntuarias. Su difusión en publicaciones despertó el interés de muchos coleccionistas que no dudaron en hacerse cada vez con más piezas de este tipo. Además, si desde las clases altas de la sociedad sí hubo una preocupación por la conservación de las obras de arte, en la España de la primera mitad del siglo XX se desarrollaron unos condicionantes que, desde los otros sectores de la sociedad, propiciaron su enajenación y venta. Entre estos destacarían la falta de valoración del patrimonio y la superioridad de la propiedad privada frente al bien público, la falta de recursos económicos de los vendedores y la idea de que lo antiguo -y por ende muchas antigüedades- eran un lastre para el progreso del país. ${ }^{9}$ 
Esta revalorización de las artes decorativas vino por distintas vías. De una parte, gracias a iniciativas como la de la Sociedad Española de Amigos del Arte y a las exposiciones públicas que esta institución organizaba anualmente en Madrid desde 1909. Cada año dedicaban sus estudios a un asunto en base a sus propios intereses -el de los coleccionistas, que eran los principales prestadores de obras de arte- y a la evolución del mercado. Todo ello quedaba editado en un catálogo de la muestra ricamente ilustrado. El mueble, por su importancia, fue uno de los primeros en ser analizados y, en 1912, se organizó una exposición que lo tuvo como objeto protagonista en Madrid y otra en 1924 en Barcelona. En ellas, y como reza el título, se mostraron las principales piezas españolas de los siglos XV, XVI y primera mitad del XVII que estaban en ese momento en manos de coleccionistas y anticuarios (Fig. 1). ${ }^{10}$ Además, a lo largo de los años y según se iban sucediendo las muestras, otras piezas de mobiliario también fueron expuestas como atrezzo y adecuación decorativa a las salas de exposición ${ }^{11}$. Fuera de esta Sociedad, otra de las exposiciones que tuvo un gran éxito en cuanto a la muestra, estudio y difusión del arte y artesanías españolas fue la Exposición Internacional de Barcelona de 1929, donde no sólo se exhibieron muebles, sino toda suerte de antigüedades de cara a un público tanto nacional como internacional. Como en ocasiones anteriores, fueron los coleccionistas/marchantes los que presentaron las mejores piezas. ${ }^{12}$

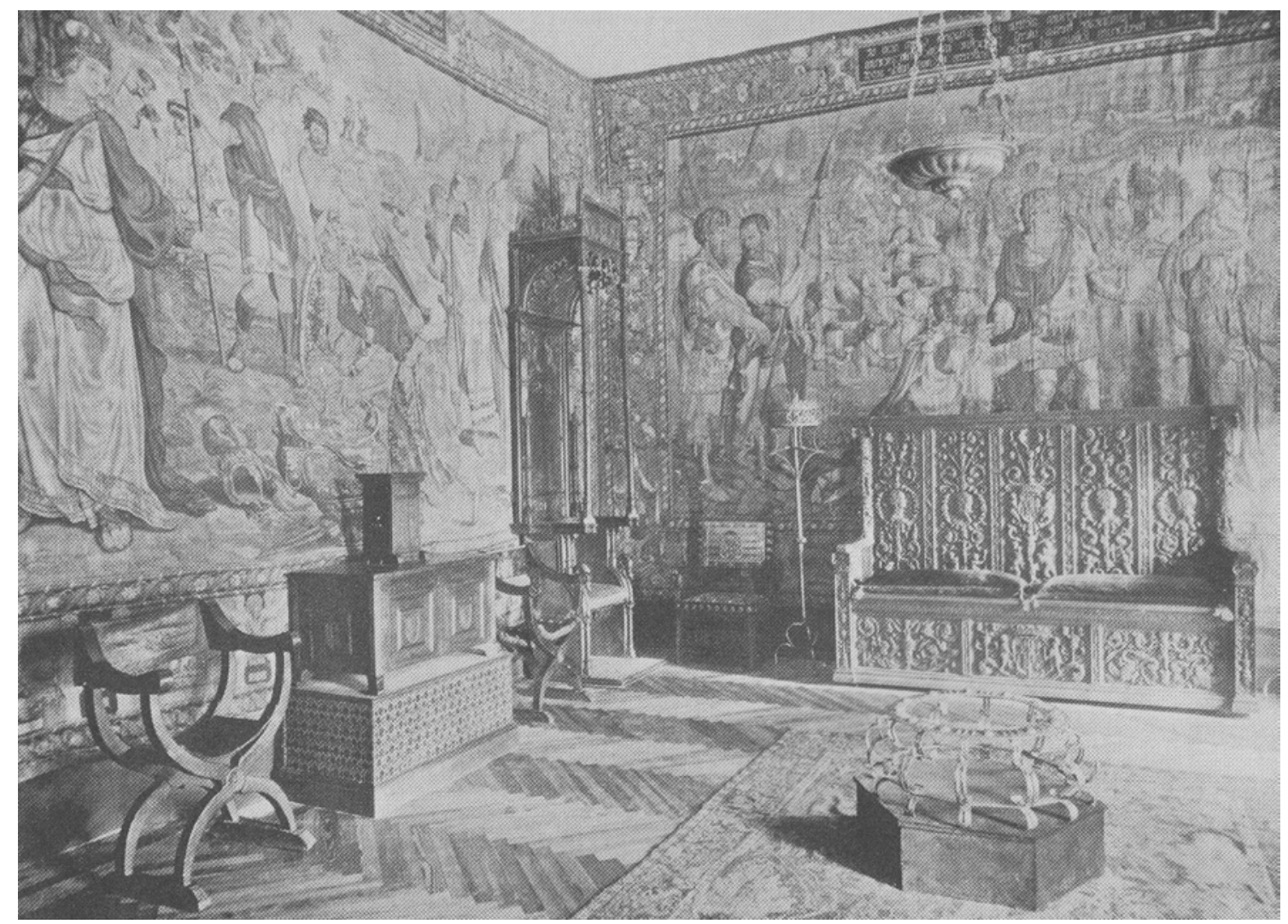

Fig. 1 Sala de la exposición en Madrid. Reproducida en Byne, Spanish Interior and Furniture. 
La importancia del mobiliario histórico español durante la primera mitad del siglo XX también se pudo ver reflejado en los estudios que se le dedicaron en publicaciones científicas periódicas de nueva creación como el Boletín de la Sociedad Española de Excursiones o Arte Español. Revista de la Sociedad Española de Amigos del Arte. Además de éstas, los libros también cumplieron la función de propagar y difundir las artes suntuarias españolas, pero no solo lo hicieron por España, sino también por América del Norte. Los catálogos de las exposiciones antes mencionadas fueron ampliamente distribuidos por ambos territorios, como también lo hicieron números sueltos de estas revistas.

Llama la atención que, además de este envío constante de publicaciones especializadas en artes decorativas y antigüedades y, en definitiva, sobre el diseño y la decoración de interiores españoles a territorios americanos, muchas de ellas se tradujesen o se escribiesen directamente en inglés. Sobre mobiliario cabría señalar la traducción del libro de Doménech y Pérez Bueno bajo el título Antique Spanish Furniture, aunque de mucho mayor calado fue la edición de Spanish Interiors and Furniture. Redactado directamente en inglés por Arthur Byne y Mildred Stapley, era un compendio de fotografías de mobiliario español y de interiores de residencias que mostraban su disposición según la moda y gusto del momento. (Fig. 2) A este libro le siguieron otros escritos editados por ellos mismos para los lectores americanos, dando así a conocer gran número de producciones artísticas españolas en aquel territorio. ${ }^{13}$

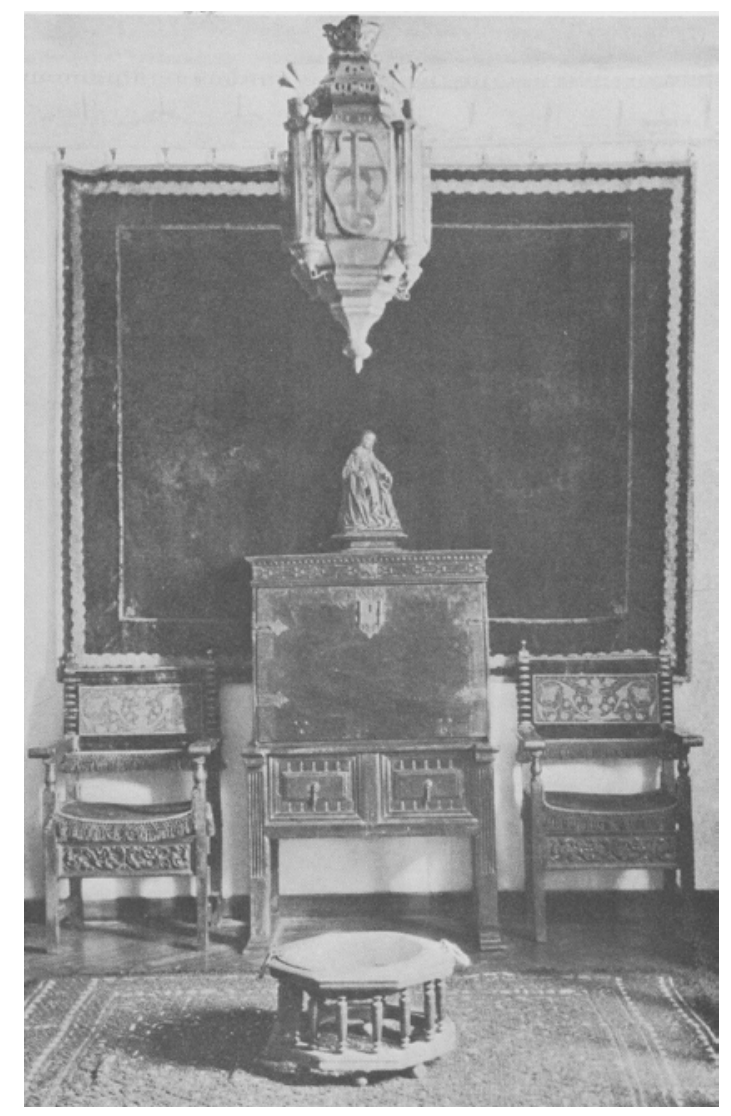

Fig. 2 Salón de la casa de Arthur Byne. Reproducido en Byne, Spanish Interior and Furniture 
Según ha quedado demostrado ${ }^{14}$, todas estas publicaciones, las exposiciones y sus catálogos sirvieron al mismo tiempo como una muestra de los objetos artísticos disponibles en el mercado nacional e internacional de antigüedades. No fueron pocas las piezas que después de aparecer en una muestra, cambiaban de propietario, o que, después de haber sido publicadas y estudiadas, eran adquiridas por un coleccionista norteamericano. La correspondencia entre los coleccionistas y sus intermediarios comerciales a uno y otro lado del Atlántico, demuestra que, para introducir ventajosamente una pieza en el mercado, aludían a que aparecía publicada en tal o cual revista, o que se había incluido en una exposición y consecuentemente en su catálogo. ${ }^{15}$ Podemos afirmar, por tanto, que detrás de la gran labor de difusión de todas estas iniciativas culturales, había un oscuro e interesado negocio de compraventa de antigüedades a escala internacional, y los coleccionistas/marchantes fueron los principales partícipes de ello, buscando un rápido beneficio económico. Además, las revistas especializadas en esta acumulación o atesoramiento de obras, como la titulada Coleccionismo, insertaban anuncios de casas de antigüedades y futuras ventas patrimoniales que se iban a llevar a cabo en ellas.

Es importante mencionar ahora, por qué los principales compradores de antigüedades fueron los americanos. Si en nuestro país estas piezas eran denostadas como antiguas, su valoración y uso era escaso y se intentaban cambiar por piezas más modernas, y, además, sus supuestos valedores y protectores se dedicaban a coleccionarlas y a mercadear con ellas en busca de un beneficio económico; es normal que no tardasen en aparecer las redes clientelares para su enajenación y exportación allá donde sí se empezaba a valorar todo lo que tuviera que ver con la historia, el arte, la literatura o la música popular españolas: Estados Unidos.

El redescubrimiento de la Península Ibérica por parte de los americanos fue paulatino y paralelo a la revalorización que en España vivieron las artes decorativas y las antigüedades. Empleamos la palabra redescubrimiento, pues a principios del siglo XIX, su visión de nuestro país estaba sumergida en la denostada "leyenda negra" y cargada de romanticismo. Se pensaba que era un país agotado en sus costumbres y en ruinas; a través de los tópicos folclóricos y estereotipos como el baile y los toros, se concebía a España -incluso en comparación con los demás países de su entorno- como un lugar atrasado, poblado por personas pobres, vagas e ignorantes incapaces de defender su imperio, de industrializarse y con una fuerte herencia musulmana. ${ }^{16}$ James Jackson Jarves llegaría a decir en 1871 "the lowest ascetic standart... anything worthy of serious study" 17 al referirse a todas las producciones españolas, salvo a los pintores Velázquez y Murillo.

Esta visión de España, principalmente propiciada a través de la literatura y las opiniones tan negativas que dejaban los embajadores americanos en España -entre ellos Mordecai Noah, Alexander Everett, Caleb Cushing-, fue cambiando ligeramente con el paso de los años, y no sólo se buscaron y se pusieron en valor las raíces hispano-mexicanas de origen californiano, sino que hubo un acercamiento a través del academicismo ${ }^{18}$. Se fundaron los primeros departamentos de historia, arte y literatura españolas en las universidades americanas, lo que contribuyó al estudio y valoración de nuestra cultura. En las 
últimas décadas del siglo XIX y principios del XX se impartieron las primeras clases en Estados Unidos sobre la historia y literatura españolas y, casi al mismo tiempo, artistas y académicos realizaron sus primeros viajes a nuestro país: unos en busca de influencias pictóricas -como Mary Cassatt, Singer Sargent o Merrit Chase- y otros para realizar sus investigaciones. Georgiana Goddard King y Arthur Kingsley Porter serán recordados a nivel histórico-artístico por ser los primeros en acercarse a la arquitectura románica producida al filo del Camino de Santiago ${ }^{19}$. Sus estudios efectuados sobre el terreno entre 1910 y 1920, respectivamente, se reflejarán en libros y artículos, difundiendo entre la opinión pública estadounidense el pasado medieval de nuestro país.

Estas publicaciones, a las que habría que sumarle algunas monografías sobre los principales artistas españoles ${ }^{20}$, afianzaron el conocimiento sobre las producciones españolas en Estados Unidos y dieron lugar a que, finalmente, nuestra cultura, incluidas artes decorativas y antigüedades, se apreciaran más y mejor. Cabría señalar, finalmente, la contribución a la transmisión y propagación de "lo español" de las Exposiciones Internacionales de Columbia (1893) -todavía con un marcado carácter romántico-, Buffalo (1901) -en la que destacó la recreación de arquitecturas emblemáticas como la Giralda- o San Diego (1915). En esta última, parte de los edificios se realizaron con el denominado Spanish Colonial Revival Style, una mezcla de estilos entre el gótico, el renacimiento y el barroco españoles y los estilos arquitectónicos de ellos surgidos y utilizados en las colonias americanas; una especie de homenaje a la importancia de España en la construcción de las identidades americanas y cuyo empleo se extendió en California y Florida ${ }^{21}$.

Los grandes coleccionistas norteamericanos, magnates de la industria surgidos desde 1870 al calor de la industrialización del país, pronto se hicieron eco de la nueva tendencia y, junto con obras europeas, también coleccionaron arte español. Nombres como Isabella Stewart Gardner, Widener, John Pierpont Morgan, los Havemeyer, Frick, Altman, Lehman, George Blumenthal, Archer Milton Huntington, Charles Deering o Hearst han quedado en la memoria de todos, aunque serán estos dos últimos los que más se interesen por el mobiliario español. A decir verdad, las artes suntuarias de nuestro país jugaron un papel importante en el coleccionismo de obras de arte españolas en América, ya que éste no sólo se limitó a los grandes maestros de la pintura. Tejidos, hierros, cerámica, platería o mobiliario, supusieron desde la entrada en el siglo XX, los elementos perfectos en la decoración de sus residencias neoyorquinas. Este tipo de obras de arte fueron gustando por su funcionalidad y disponibilidad y colmaron el mercado artístico entre España y América del Norte. Los mencionados coleccionistas no fueron los únicos aficionados a estas piezas; otros cuyos nombres han caído en el olvido, también se interesaron por las artes decorativas y el mobiliario español.

Ante la demanda americana y para hacer frente al mercado, surgieron nuevas casas de subastas y negocios de antigüedades en el país, y, consecuentemente, las salas europeas buscaron abrir sucursales y establecerse en Nueva York. Para el caso español, fueron los propios coleccionistas/marchantes los que exportaron los objetos que poseían para venderlos en estas galerías, aunque también trabajaron por comisión, buscando obras concretas o de un arte 
y estilo determinados y para clientes particulares, como hiciera Arthur Byne para Hearst ${ }^{22}$ o Benigno de la Vega Inclán con el expolio de varias pinturas de El Greco.

Para ellos era un negocio exitoso. Si en España la adquisición de mobiliario era bastante sencilla por el amplio mercado existente, su exportación también fue fácil. El paso de las mercancías por las aduanas y previamente por la Comisión de Valoración del Tesoro Artístico Nacional -el organismo que daba el visto bueno para la exportación- estaba lleno de ocultaciones y fraudes: muchas veces se declaraban menos objetos de los que realmente se llevaban, se falseaba su antigüedad -mayor de 100 años era inexportable- o se franqueaba el paso por un puerto de salida no autorizado. Tampoco las leyes españolas ayudaron a contener la exportación en la primera mitad del siglo XX, pues, aunque en la teoría estuviesen bien concebidas, en la práctica no se pudieron llevar a efecto por la indefinición terminológica -lo que dificultaba su interpretación-, la falta de presupuesto estatal para la protección de Bienes muebles o inmuebles o, simplemente por la superioridad de otras disposiciones.

La subasta fue la principal vía de entrada de las antigüedades españolas en territorio americano. Durante los años iniciales del siglo XX y hasta los años 30, muchos coleccionistas/marchantes españoles preferirán poner a la venta sus posesiones directamente en Nueva York mediante este método, pues les permitía el transporte de un gran número de objetos a través de los trasatlánticos -lo que ahorraba costes- y tras realizar la venta, se procuraban un gran beneficio económico: lo que les había costado unas cuantas pesetas en nuestro país, era revendido en dólares a unas cantidades considerablemente más altas.

La familia de los Ruiz -Pedro, Luis y Raimundo- fueron los pioneros en el negocio de la exportación y venta de antigüedades en Nueva York ${ }^{23}$; a ellos se les debe, entre 1919 y 1936, un total de 19 subastas -cada una conteniendo entre 700 y 900 lotes- en las distintas galerías de la ciudad: Clarke's Auction Rooms, Anderson Galleries y la American Art Association. También cabría destacar la subasta de los Weissberger en 1921 en la American Art Association ${ }^{24}$ o la protagonizada por el conde de las Almenas en $1927^{25}$. Además, aunque su método de venta no fuera éste, sino la consignación directa en las distintas galerías, también fue considerable el volumen de piezas que, gracias a su nutrida red de agentes en España, enviaba año tras año Thomas Harris desde su tienda de antigüedades en Londres, la Spanish Art Gallery.

En cuanto al mobiliario vendido a través de estas vías, podríamos destacar como elemento más subastado, las mesas españolas del siglo XVII, tanto las lisas como las que contienen cajones. Por ejemplo, en una sola subasta, la de los Ruiz de 1919, se referencian más de 15 de este tipo, además de varias sillas de cuero con brazos (lotes $n^{\circ}$ 605-611). En una subasta posterior, la de diciembre de 1925, vuelven a aparecer este tipo de objetos, pero añadiendo al conjunto de objetos subastados, todos de los siglos XVI al XVIII, puertas de entrada de edificios como iglesias o monasterios, sillas fraileras, bargueños, mesas abatibles o arcones (lotes n ${ }^{\circ} 120-199$ y 292-407). En otras, como las de 1926, y en las siguientes, el mobiliario subastado por los Ruiz se vuelve a repetir en sus distintos tipos (lotes $\mathrm{n}^{\mathrm{0}} 114-161,306-355$ y 505-547), destacando también las puertas de entrada (lotes $n^{0} 187-197,372-380$ y 563-570), como una hispano-morisca 
procedente de Granada. También esta familia se procuró piezas más grandes y suntuosas y quizás, más difíciles de sacar de nuestro país como sitiales de coros (lote $\mathrm{n}^{\circ} 913$ de la subasta de 1919) (fig. 3), sillerías de coro renacentistas completas (lote $\mathrm{n}^{\circ} 193$ de la subasta de diciembre 1925) o grandes y robustos sofás de madera (lotes $\mathrm{n}^{0} 177$ y 191 de la subasta de 1926).

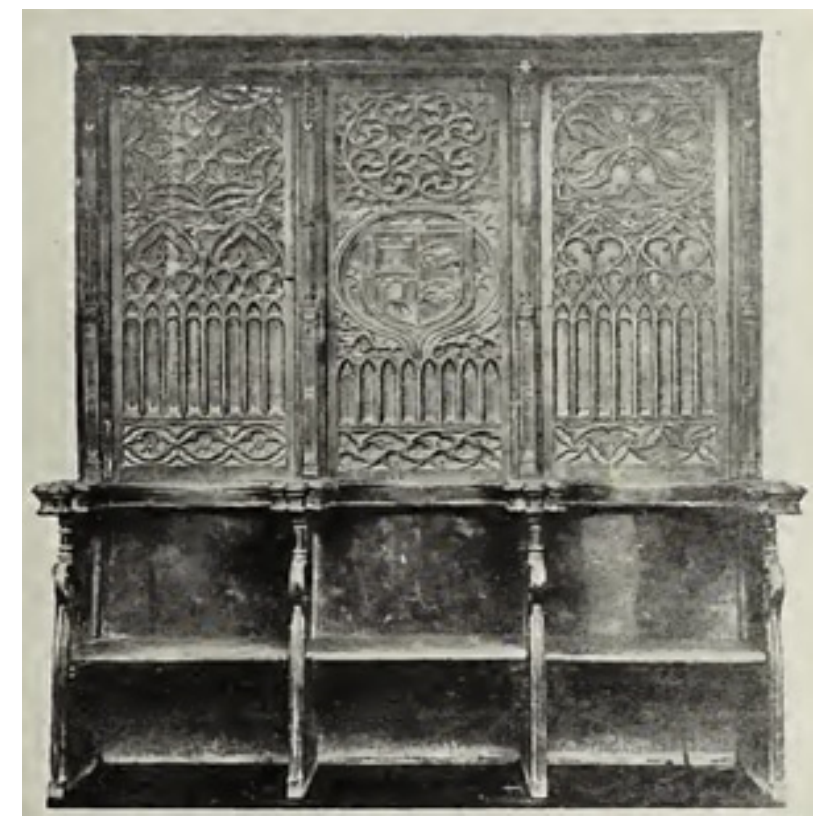

Fig. 3 Sitiales de coro subastados por los Ruiz en 1919. Reproducido en el catálogo de la subasta.

En cuanto a los hermanos Weissberger, en su Spanish Art Treasures organizada en 1921 en la American Art Association, se subastaron 331 piezas de mobiliario agrupadas en 255 lotes, aunque no todos españoles. En los que sí nos concierne, como en el caso de los Ruiz, vuelven a aparecer sillas y sillones fraileros de los siglos XVI y XVII (fig. 4), así como sofás, sillones y mesas de la más variada tipología. También aparecen algunos bargueños, arcones de novia, armarios de estos siglos y en mucha menor medida, puertas de entrada (lotes $\mathrm{n}^{\circ} 687$ al $780 \mathrm{y}$ 860 al 916). Además, llama la atención la introducción en la subasta de algunos ejemplares sueltos del siglo XVIII imitando mobiliario de asiento francés.

Finalmente, con la liquidación del conde de las Almenas, mucho menor en cantidad y calidad que las anteriores en lo que a mobiliario se refiere, aparecen subastados muebles de estrado (lote $\mathrm{n}^{\circ} 139$ ), y, como en los casos anteriores, sillones fraileros de cuero (por ejemplo lotes $\mathrm{n}^{\circ} 147$ y 150) o tapizados en seda (lotes $\mathrm{n}^{\circ} 288,290$ o 366 entre otros), algunas mesas del siglo XVI (por ejemplo lotes $\mathrm{n}^{\circ} 154,276,281$ ), arcones y armarios (por ejemplo lotes $\mathrm{n}^{\circ} 280-283$ o el $\mathrm{n}^{\circ}$ 400), (fig. 5), bargueños (por ejemplo lotes $n^{\circ} 408-410$ ), trozos de sillerías de coro (lotes $\mathrm{n}^{\circ} 295,375$ y 416) o por el contrario, algunas piezas raras como para ser subastadas y que nos revelan el gusto de su propietario, como una cama (lote $\mathrm{n}^{\circ}$ 312), una silla de manos (lote $n^{\circ} 405$ ) (fig. 6), un costurero (lote $n^{0} 287$ ) o -a pesar de ser muy comunes entre los coleccionistas- un cofre mudéjar del siglo XIV (lote $\mathrm{n}^{\circ} 268$ ) y otro más, siguiendo su estilo, del siglo XVI (lote $\mathrm{n}^{\circ} 277$ ). 


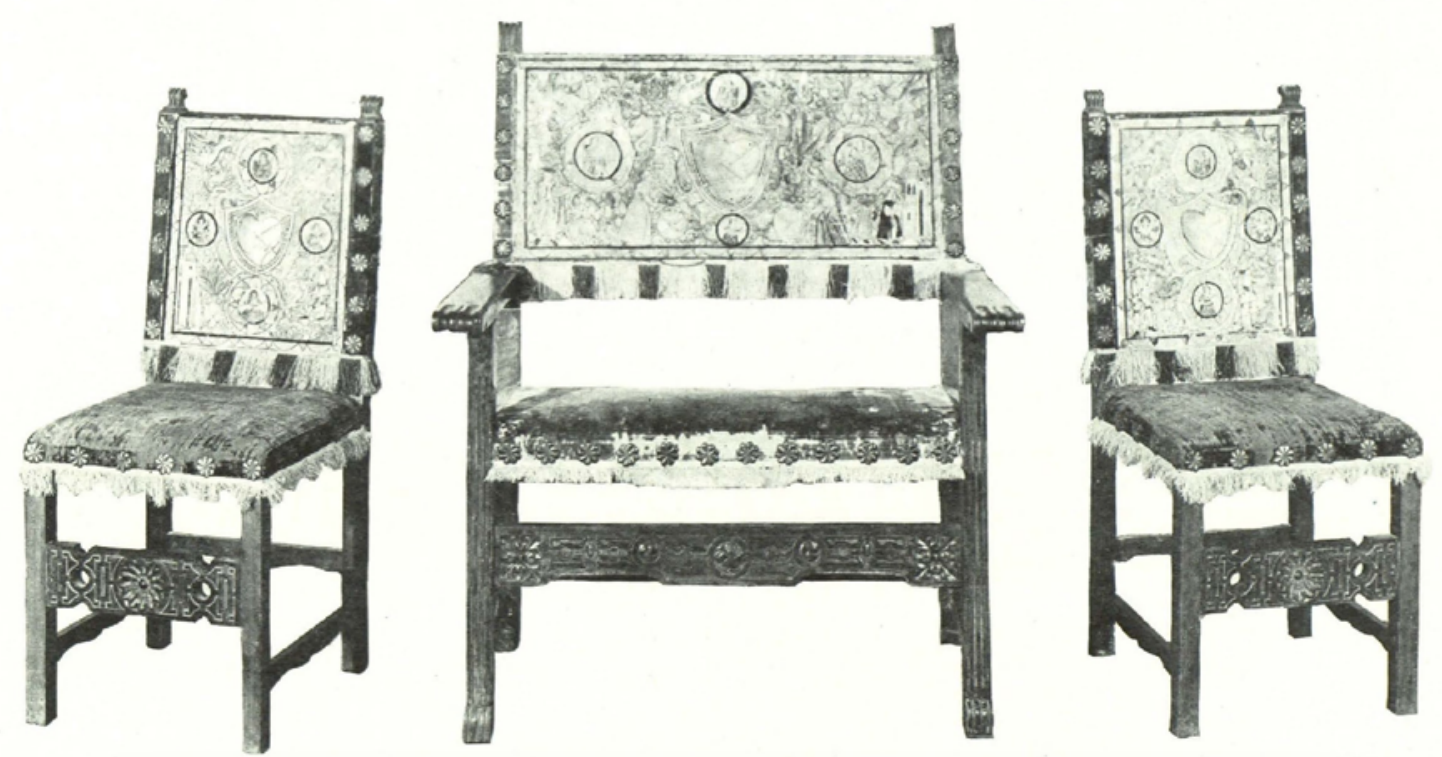

Fig. 4 Sillas y sillón frailero subastado por Weissberger en 1921.

Reproducido en el catálogo de la subasta.

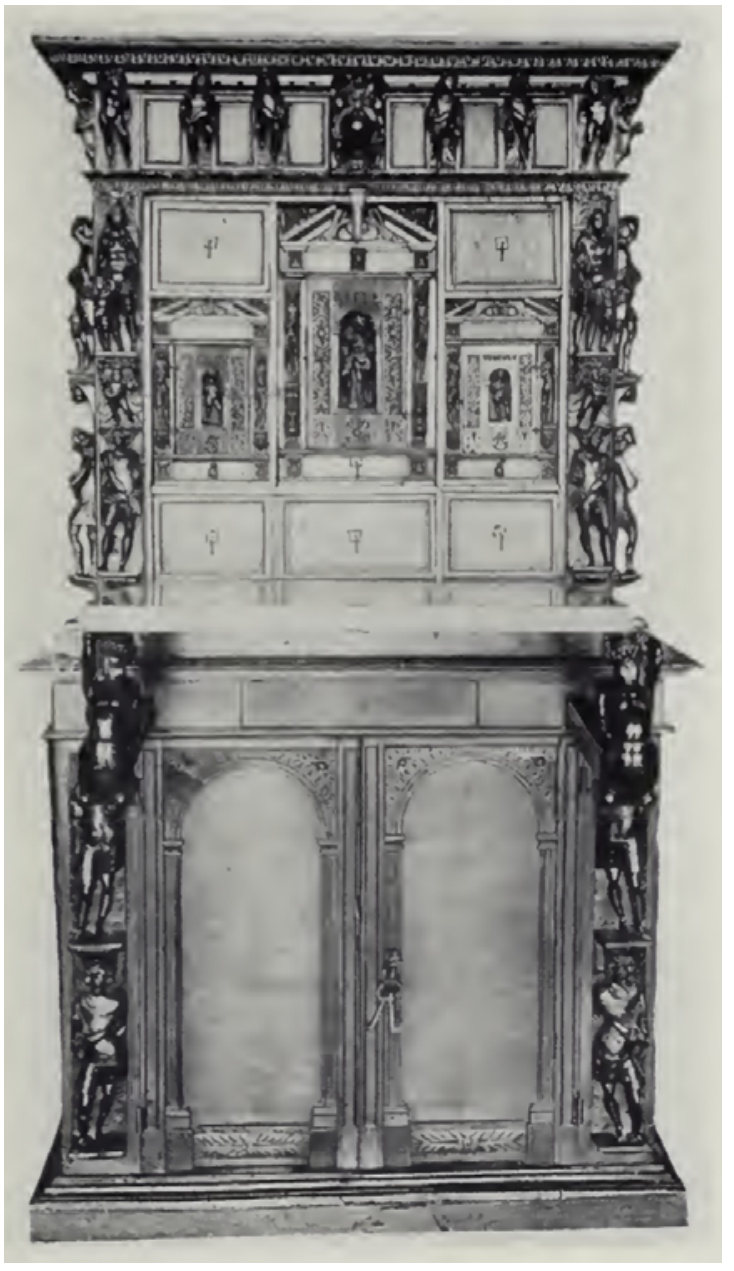

Fig. 5 Armario estilo Carlos V subastado por el Conde de las Almenas en 1927.

Reproducido en el catálogo de la subasta.

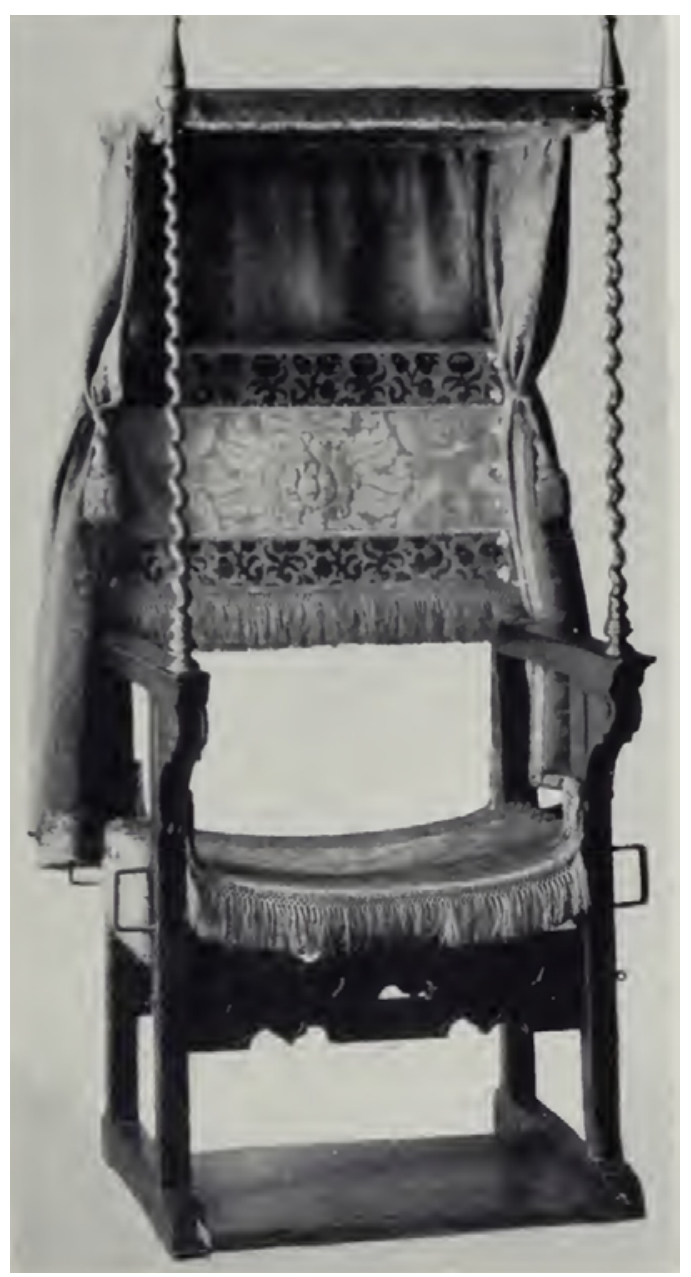

Fig. 6 Silla de manos subastada por el Conde de las Almenas en 1927.

Reproducido en el catálogo de la subasta. 
Sirvan estos ejemplos para hacernos una idea del tipo de objetos que eran demandados en América. Como cabría esperar, el influjo del Spanish Colonial Revival Style estaba presente y por ello las piezas más deseadas eran las pertenecientes a los periodos del renacimiento y barroco españoles, las más tradicionales. Es más, si nos fijamos en las primeras páginas de los catálogos de las subastas, se especifica claramente -y esto servía para llamar la atención- que el mobiliario a adquirir era del primero de estos periodos -subasta de los Ruiz de diciembre 1927- o que había a la venta unos ejemplares excepcionales de bargueños españoles -subasta de diciembre 1926-. Ocurría también lo mismo con piezas de mobiliario barroco, donde incluso se daba su procedencia geográfica dentro de España, como así se publicita en la de diciembre de 1925. Por lo mismo, aunque en mucha menor medida, el mobiliario gótico -como arcones de novia, cofres revestidos de seda o cajas de cuero- estuvo bastante presente y también fue adquirido en masa. Finalmente señalaremos que la herencia morisca se hizo notar de manera escasa, a pesar de su carácter exótico, y apenas se referencian algunas piezas de gran tamaño, cuando, por ejemplo, las arquetas con taraceas eran muy valoradas por los coleccionistas españoles, pero no así por los americanos.

Por otro lado, aunque las producciones dieciochescas estuvieron muy ligadas al barroco, no son éstas las obras las que más se venden, aunque sí causaran interés, mientras que hay una falta absoluta de demanda de mobiliario del siglo XIX, a pesar de que en realidad era el único exportable legalmente. Ni rastro de los estilos Carlos IV, isabelino o fernandino.

Como dijimos, todas estas piezas, una vez subastadas, fueron a parar a manos de coleccionistas quizás no tan famosos y conocidos como los de la Gilded Age. Para saber quieres fueron, hay que ir más allá y buscar en los archivos de las galerías que recibían mobiliario de su parte, una vez que se querían deshacer de una obra en concreto. Ni que decir tiene, que también eran estas empresas las que acudían a las subastas para conseguir piezas para luego revender. French \& Co fue uno de estos casos y, dedicado desde sus inicios a las artes decorativas, por sus manos pasaron muchos ejemplares de muebles españoles.

Sabemos, pues se han conservado todas las hojas de inventario de las piezas que estuvieron temporalmente en esta galería a lo largo de sus años de actividad (1907-1968), que por sus puertas entraron y salieron -tras ser revendidos- un total aproximado de 450 conjuntos de mobiliario español. ${ }^{26}$

En lo que se refiere a obras de arte españolas, con el primero con el que establecieron contacto comercial fue con el anglo-español Harris, quien supo aprovechar desde 1910 de manera eficiente la consignación de obras suyas en la galería. Por ejemplo, suyos fueron: un arca del siglo XVI recubierta de terciopelo, revendida en 1933 al Kansas City Museum; dos puertas de entrada de madera del Palacio de Carlos V en Granada -según la correspondiente hoja de inventario-, recompradas años más tarde por el coleccionista H. Sanderson; un sillón de terciopelo naranja con el escudo de armas de Felipe V -y según se apunta, procedente de Orihuela-, comprado posteriormente por Mrs. Stotesbury; una mesa del siglo XVII con dos cajones, adquirida ya en 1963 por la galería La Porto D’Oro; o tres sillones fraileros de este mismo siglo abonados cada uno y en diferentes años por los coleccionistas Luis Miranda, Paul Newman y la galería Coleman. ${ }^{27}$ 
French \& Co también supo aprovechar la ingente cantidad de mobiliario que llegaba con las subastas de la familia Ruiz, y a ellos les compraron, sólo por poner diversos ejemplos: un bargueño del siglo XVI -lote $\mathrm{n}^{\circ} 916$ de la subasta de mayo de 1919 en Clarke's- comprado en diciembre de ese mismo año por Charles Deering; una mesa de nogal con dos cajones -lote $\mathrm{n}^{\circ} 112$ de la subasta de junio de 1924 en Clarke's- adquirido en 1926 por Mr. H. W. Chadbourne; otro ejemplar como el anterior -lote $\mathrm{n}^{\circ} 433$ de esta misma subasta- abonado al año siguiente por Walter P. Chrysler; un conjunto de cuatro sillas y un sofá -lote $\mathrm{n}^{\circ} 363$ de la subasta de 1926 en la American Art Association y procedentes según la ficha de inventario del Palacio de Aranjuez-, que fue dividido respectivamente en 1926 y 1928, entre los coleccionistas E. F. McCann y M. C. Partos; y también 28 sillerías de coro, lo que podría corresponder a un coro completo, realizadas -según se indica en la ficha- por Rodrigo Alemán y vendidas por la galería en 1942 a la también galería Helm. ${ }^{28}$

Como hemos dicho antes, aunque la subasta fue la principal vía de llegada de nuevas piezas, la galería también recibió mobiliario de otros coleccionistas, ya fuese por venta directa, por su presencia en las subastas, o por compra a otras galerías. Por ejemplo, Miss Gheen se deshizo en 1918 de un cabecero de cama ricamente decorado y policromado que John Wanamaker adquirió a French \& Co en 1923; W. H. Farr dejó en la galería una mesa con patas torneadas que compró algunos años más tarde, en 1922, Joseph Widener; de la galería Keller \& Funaro, French se hizo con una sillería de coro modelo -según la hoja de inventario- de la que se instaló en el Monasterio de El Escorial y que quiso adquirir años más tarde el coleccionista León Schinasi; en la subasta de 1924 del coleccionista Tolentino en la American Art Association, la galería se hizo con un armario del siglo XVI abonado al año siguiente por Mrs. Mesker; y citaremos, por último, un banco en madera de nogal del siglo XVI -lote ${ }^{\circ} 298$ de la subasta de Lefortin en la American Art Association- abonado finalmente por Henry Huntington, tío de Archer Milton Huntington. ${ }^{29}$

Aunque no podemos extendernos más en dar ejemplos, los hay, como dijimos, por cientos, no sería justo acabar este apartado de la dispersión del mobiliario español propiciado por las galerías, sin mencionar antes algunas compras que el mayor acaparador de objetos españoles de la época, William Randolph Hearst, realizó a la galería French \& Co. Fue éste su mejor comprador, aunque, a decir verdad, adquirió piezas a esta galería y a todas las demás repartidas por Nueva York y otros puntos de Estados Unidos. Podríamos apuntar: unas puertas del siglo XVI en las que aparecen unos santos pintados que la galería había recibido previamente de Demotte; un bargueño procedente de la coleccionista Summer Healey; un banco de nogal que French había adquirido previamente a Thomas Harris; o una cama completa -cabecero y travesaños- de la subasta de Raimundo Ruiz en la American Art Association de diciembre de 1926 -lote n ${ }^{\circ} 183 .^{30}$

Hubiéramos deseado tener la oportunidad de acceder a los archivos de otras casas de antigüedades para saber si la cantidad y calidad de mobiliario que movió French \& Co en Nueva York se ha podido ver reflejado también en ellas; pero para acabar, nos gustaría mencionar que del furor por lo español y sus artes decorativas no sólo se hicieron eco los coleccionistas norteamericanos y a la larga las galerías de las principales ciudades -que consiguieron 
incrementar la circulación y atesoramiento de estas obras-, sino que también se vieron beneficiados los museos, que pronto adquirieron algunas piezas señeras de mobiliario español para sus fondos (fig. 7).

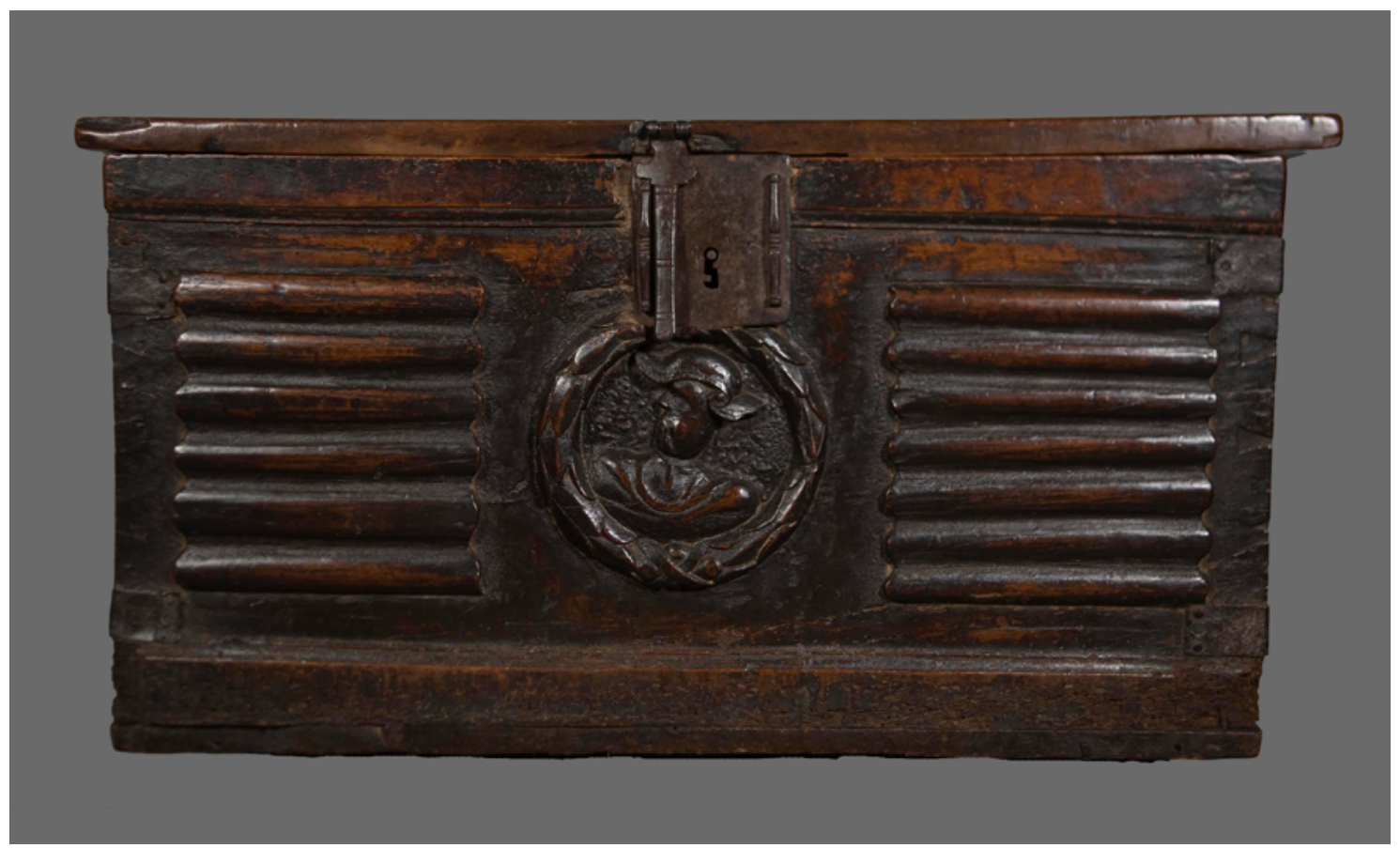

Fig. 7 Arcón de novia (Burgos), lote 914 de la subasta Weissberger. Isabella Stewart Gardner Museum. F19e48.

\section{Caminos de vuelta: El mueble y la reconstrucción del mercado de antigüedades tras la Guerra Civil}

Hasta los años 30 del siglo pasado, las subastas de arte español se sucedieron en territorio americano, si bien hay que decir que el Crac de 1929 tuvo unas repercusiones muy negativas en la demanda de piezas procedentes de nuestro país, y tras este hecho, salvo una venta protagonizada por los Ruiz en 1936, el ritmo de transacciones bajó considerablemente. Esto se puede contrastar fácilmente si nos fijamos en la cantidad de objetos vendidos por French \& Co antes y después de esta fecha; así, por ejemplo, si en 1924 y 1927 se vendieron respectivamente 50 y 42 lotes de muebles españoles a través de esta galería, a partir de 1931 -y hasta 1963- apenas se referencian cinco operaciones al año de estas características.

La crisis de 1929 provocó la ruina de muchos coleccionistas que tuvieron que poner a la venta sus posesiones artísticas y asumir su desmembramiento. Esto indujo a un aumento en la oferta de obras de arte españolas y, también, a una escasa demanda por parte de coleccionistas y galeristas que ya no estaban en situación de poder adquirirlas. En los años posteriores y como consecuencia de ello, el precio del mobiliario -y de todas las artes decorativas y antigüedadesbajó considerablemente. Además, otro de los hechos por el cual el precio de este tipo de objetos se vio afectado, fue la reorientación del gusto español hacia los 
grandes maestros de la pintura, que vieron revalorizados al alza sus precios. El mercado interno americano era suficiente para conseguir todo tipo de artes suntuarias de calidad a precios bajos y por ello, no hacía falta demandar piezas del exterior para ser importadas, subastadas y vendidas.

Cuando el mercado americano recobraba levemente su pulso en lo que se refiere a la compraventa de antigüedades, dio comienzo en nuestro país la Guerra Civil. Aun sin que ello fuera absolutamente determinante, la exportación de objetos se vio paralizada por la contienda bélica y también la actividad comercial dentro de nuestras fronteras por parte de los anticuarios. La destrucción dio paso al pillaje y saqueo de algunas piezas de las que tan sólo se beneficiaron algunos coleccionistas. A raíz de ello, el nivel de transacciones de antigüedades no llegó nunca a alcanzar los parámetros en los que se había situado antes de 1936.

Tras la Guerra, en 1940, los galeristas españoles tuvieron que reinventarse para sacar sus empresas adelante y, ante la falta de obras y de stock que vender en el mercado nacional -piénsese que, a los estragos de la acción bélica, se sumó la continua exportación de las mejores piezas propiciada en los decenios anteriores-, para salvar sus negocios, pusieron la mirada en las obras que se encontraban en América del norte y que otrora ellos mismos habían exporta$\mathrm{do}^{31}$. Los propietarios de las tiendas españolas de antigüedades dieron de nuevo el salto a Nueva York, pero esta vez, para devolver a nuestro territorio lo que hacía algunos años ellos mismos habían exportado. Con el tiempo, acabaron reactivando y consolidando el mercado interno de antigüedades españolas.

Algunos coleccionistas españoles exiliados por la Guerra, eran conscientes de que este tipo de movimientos se estaban produciendo, y era tan evidente su conocimiento, que incluso lo dejaban escrito en las misivas que se enviaban entre ellos, lo que nos ha servido para corroborarlo. Un ejemplo de ello lo encontramos en una carta del 25 de octubre de 1946 de José Weissberger a Francesc Cambó, donde el primero -que residía en Nueva York y que estaba adquiriendo antigüedades francesas e italianas para la residencia del segundo en Buenos Aires-, le comenta:

[...] Mesa italiana de Silberman. La clavé para que no se le vaya diciéndole que no sé exactamente cuando la pagaré. Es extraordinaria. Claro que las mesas españolas me gustan mucho. Pero lo de España anda de capa caída y hubo una voga [sic] breve cuando empezó la locura de lo español en la Florida. Ahora los marchantes españoles (Linares y Ruiz) compran aquí. El otro día un Sorolla dio $\$ 13.500$. [... $]^{32}$

Comentaba aquí José Weissberger a Cambó la moda del Spanish Colonial Revival Style en Florida, que ya estaba dando sus últimos frutos en 1946, pero también la nueva entrada de comerciantes españoles a Nueva York para comprar piezas. Además, por lo que nos dicen estas líneas, parece ser que el mobiliario español en América jugó un papel importante pues debió ser uno de los objetos más apreciados.

Si acudimos de nuevo a las hojas de inventario de French \& Co, efectivamente el mueble español fue uno de los objetos más demandados, y que a la 
larga sirvió para la reactivación del coleccionismo español de antigüedades en nuestro país. Aunque en este inventario no aparezca anotado el apellido Linares -piénsese que Weissberger se podría estar refiriendo a sus adquisiciones en cualquier otro establecimiento-, sí consta el de los Ruiz.

Sólo en esta galería, Raimundo Ruiz -el encargado familiar de realizar estas compras- aparece anotado como comprador un total de 32 veces y, entre el mobiliario que adquiere, podríamos mencionar tres asientos de coro -que French \& Co había adquirido a Thomas Harris en 1919-, dos camas completas torneadas del siglo XVII, o un espejo dorado y policromado, además de otros muchos objetos entre los que cabe destacar algunos ejemplares de cerámica de reflejo metálico. ${ }^{33}$

Desconocemos qué otros muebles o cuántos compraron los anticuarios españoles a las distintas galerías de la ciudad de Nueva York, pues como señalamos en el caso anterior, los archivos de las mismas no se han conservado y es, por lo tanto, imposible cuantificar la cantidad de mobiliario importado de vuelta a España. A buen seguro fue mucho, pues, aunque solo hayamos podido rescatar el ejemplo de una de las casas de compraventa -que fue, por otra parte una de las más importantes en lo relativo a artes suntuarias-, se daban las condiciones óptimas para hacerlo: como en los años 20, también había en este caso un precio de venta muy bajo que daba a los anticuarios un amplio margen de beneficios a la hora de comprar en América y revenderlo en España. Además, por esta época, en nuestro país, se estaban volviendo a poner de moda los interiores históricos que hizo aumentar el interés de los coleccionistas por el mobiliario.

Una vez retornado -sirva este ejemplo como una muestra más de que el mobiliario ayudó en esta recuperación económica ligada al coleccionismo-, los anticuarios dispusieron del mobiliario en los escaparates y en los interiores de sus establecimientos para así llamar la atención de los viandantes y coleccionistas pues sabían que este tipo de piezas les servía de reclamo. Si comparamos la instantánea, que data de 1920, del interior de la tienda de antigüedades de García Cabrejo en Madrid (fig. 8), con la del interior de la casa valenciana de "Las Américas", cuya fotografía es posterior a 1940 (fig. 9), el cambio es claro y el elemento que más predomina en esta segunda es el mueble español. Si aparecía expuesto es porque se sabía que se vendía con facilidad.

Con el trascurrir de los años, el mueble ayudó a la definitiva normalización del mercado de antigüedades tras la guerra y, gracias a ello, en la década de los años 50, Madrid -seguida muy de cerca por Barcelona- se convirtió en una de las principales capitales europeas de dicho mercado. Se volvieron a mover agentes, galerías y coleccionistas nacionales e internacionales en busca de piezas para sus colecciones.

Una muestra de ello la encontramos de nuevo en la correspondencia que mantuvo José Weissberger en los años 50 con el alemán afincado en México, Franz Mayer. Según las misivas que estos se enviaban, se deja claro que el primero acompañó y guió por Madrid en sus compras al anticuario Ramón Aranda, que regentaba por esos años la galería El Escorial situada en la Avenida Reforma de la Ciudad de México ${ }^{34}$. No fue sólo él, sino que el propio Mayer se fio del mercado madrileño para la adquisición, a través de Weissberger, de varios objetos al anticuario Eutiquiano García Calles, entre los que se encontraban 
un bargueño español del siglo XVI, siendo esta la pieza más cara que compró -2.100 pesetas- (fig. 10). ${ }^{35}$. Por la misma fuente también conocemos que no solo fueron los mexicanos los que tras su desarrollismo económico posrevolucionario vinieron a adquirir antigüedades a Madrid, sino que también confiaron en este mercado y en el propio Weissberger varias galerías y Fundaciones de Nueva York, entre ellas la Kress Foundation. ${ }^{36}$

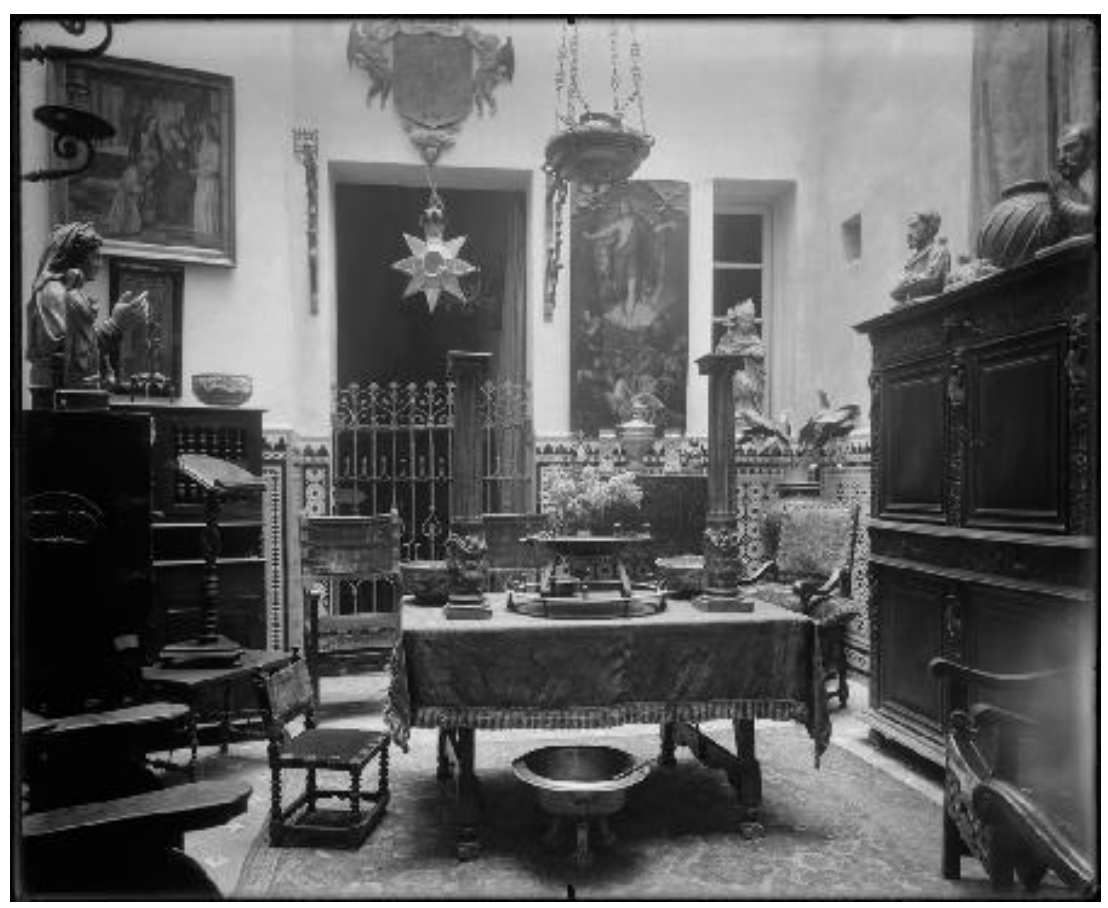

Fig. 8 Tienda de antigüedades García Cabrejo. Fototeca IPCE, Archivo Moreno, $04671 \mathrm{CP}$.

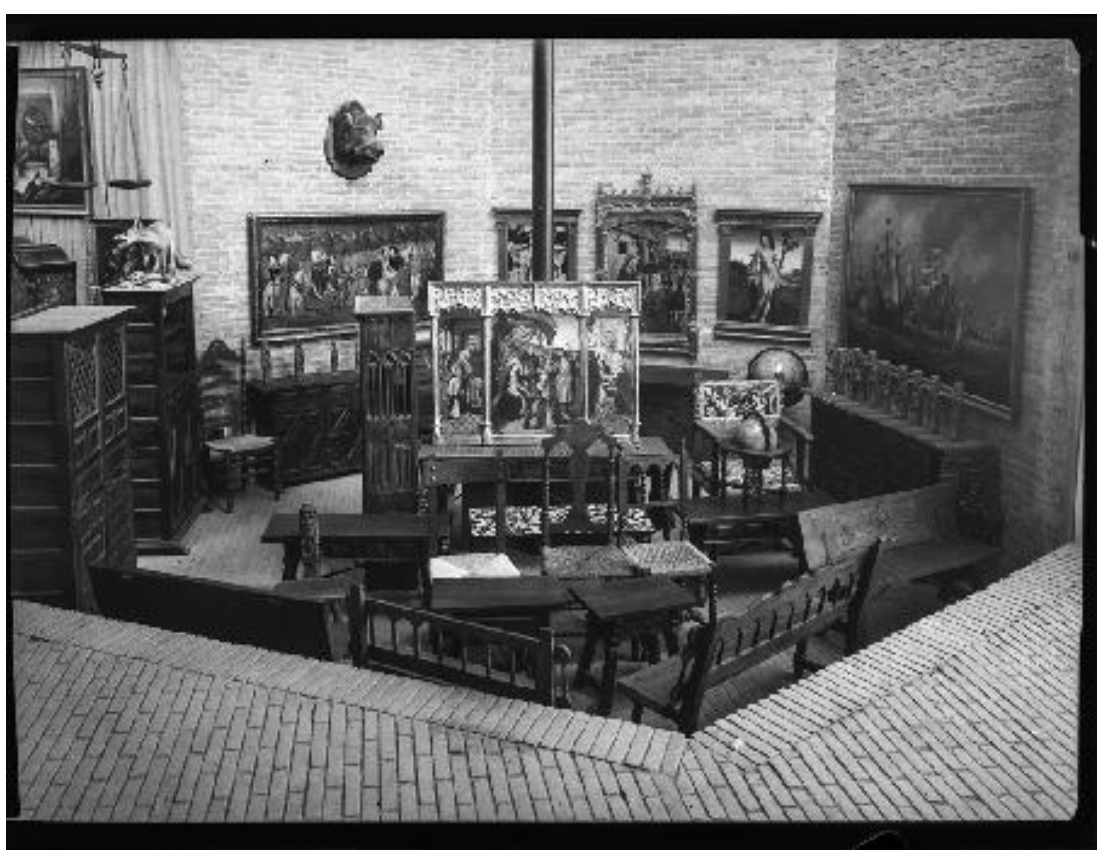

Fig. 9 Tienda de antigüedades "Las Américas". Fototeca IPCE, Archivo Wunderlich, WUN 10343 P 


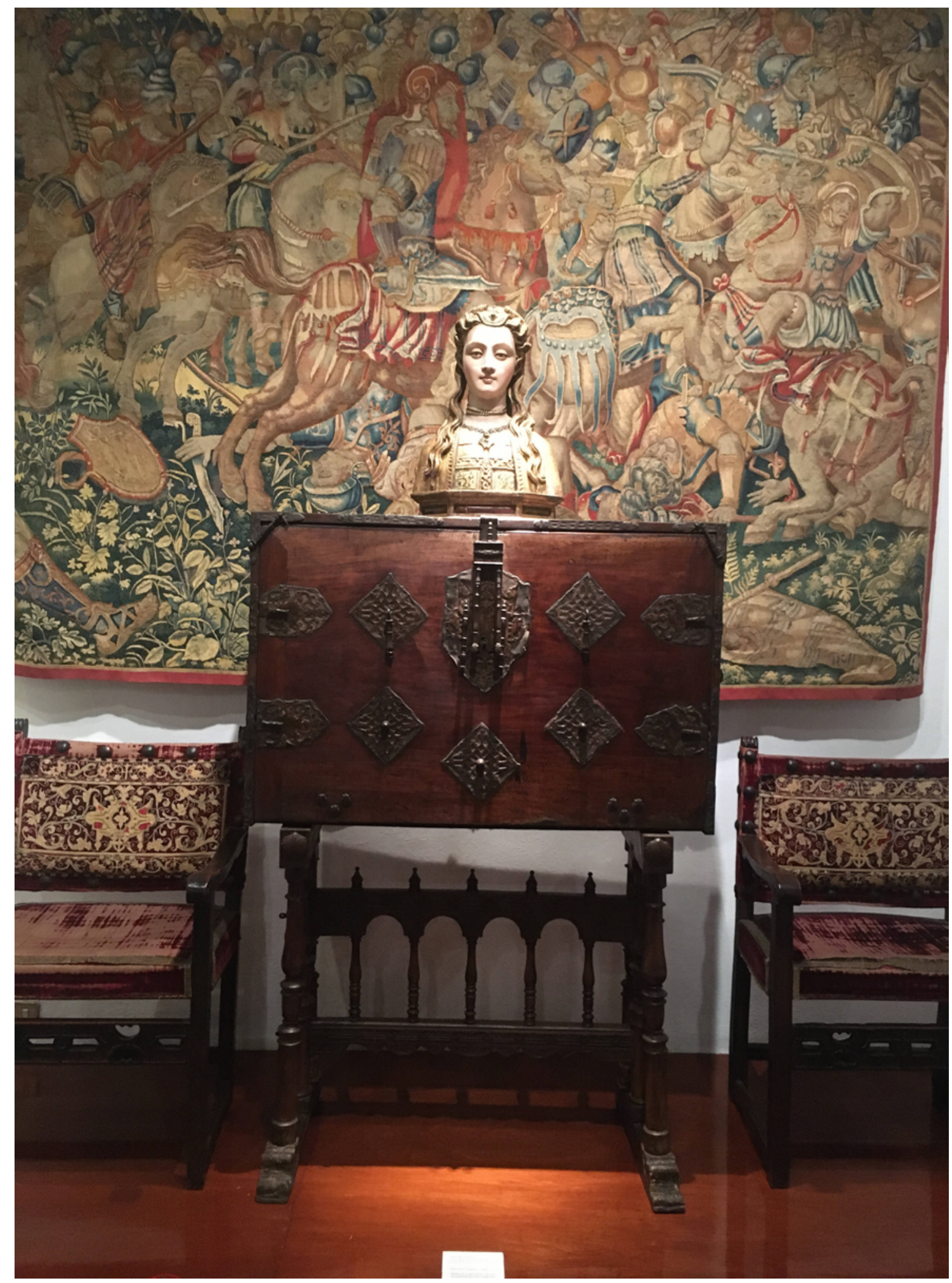

Fig. 10 Bargueño de la colección de Franz Mayer adquirido en España. Museo Franz Mayer, México. Fotografía del autor. (diciembre 2019). 
Desconocemos los objetos y obras de arte que compraron Ramón Aranda y Dianne Dwyer Modestini para su galería y para la Kress Foundation respectivamente, pero sí que es importante remarcar que tanto ellos como Mayer vinieron a buscar piezas al mercado de antigüedades de la capital española, pues este ya se había recuperado desde hace más de una década y ofrecía precios tan competitivos y atractivos para que mereciese la pena cruzar el océano Atlántico -con los costes que eso conllevaba- para hacerse con obras de calidad. El mueble español se constituyó como una pieza clave en este mercado como lo demuestra el hecho de que Mayer -que era muy selectivo- comprara un bargueño, y que esta fuera la pieza mejor valorada entre sus adquisiciones.

\section{Conclusión}

¿Fue el mueble uno de los elementos vertebradores en la recuperación del mercado de antigüedades español tras el desastre que supuso la guerra civil? Con las deducciones esclarecidas y pruebas documentales aportadas en el último apartado, creemos que así lo fue y, a falta de más investigaciones al respecto, esperamos haber sentado las bases indagatorias para futuras pesquisas sobre el mercado del mismo durante la década de los años 40.

A decir verdad, durante todo el siglo XX, el mobiliario español nunca dejó de tener gran importancia no sólo en el mercado de antigüedades español, sino también en el norteamericano, pues siempre hubo un gusto por su coleccionismo y atesoramiento fruto de la mudanza en los gustos. Durante las primeras décadas, lo que era atrayente y muy valorado al otro lado del Atlántico, lo era en España por una minoría muy selecta -los coleccionistas- que prefirieron la ganancia económica al exportar dichas piezas y venderlas -ante el estupor de las autoridades-, al hecho de conservarlas y disfrutarlas en suelo patrio, aunque también hay que decir que, a tenor de unas circunstancias concretas, hubo muchos ejemplares disponibles como para poder ser exportados.

En el caso contrario y durante la década de los años 40, lo que era denostado allí por falta de posibilidades económicas, era de nuevo valorado de manera global en nuestro país, lo que indujo a traer por parte de los anticuarios españoles algunos ejemplares de vuelta procedentes de las galerías de Nueva York y a que coleccionistas nacionales y extranjeros vinieran a España a adquirir mobiliario -a precios muy competitivos- de nuevo gracias al restablecimiento de las redes clientelares y de las tiendas de compraventa; siendo además parte de esta atracción propiciada por el reclamo expuesto en estas últimas, lo que multiplicó exponencialmente su adquisición.

Se podría decir por lo tanto que a pesar de las sucesivas crisis, mudanzas en los gustos y vaivenes de su precio, el mueble fue uno de los objetos más apreciados y valorados como pieza de colección tanto a uno como al otro lado del Atlántico durante todo el siglo XX; lo que nos permite constatar, a pesar de los cambios entre unas décadas y otras y en ambos países, su importancia dentro del mercado de antigüedades del siglo pasado. 


\section{NOTAS}

${ }^{1}$ Peter Thornton, L'Époque et son Style: la décoration intérieure (Paris: Flammarion, 1986); y Jean Baudrillard, El sistema de los objetos (México: Siglo XXI editores, 2016), 13-71.

${ }^{2}$ Entre los estudios sobre el mueble español, algunos importantes para este trabajo, aparecidos durante ese tiempo, cabría destacar: Jean-Charles Davillier, Les arts decoratifs en Espagne au Moyen Age et à la Renaissance (Paris: Pillet et Dumoulin, 1879); Juan Facundo Riaño, The industrial arts in Spain (Londres: Chapman and Hall, 1879); Francisco Miquel i Badía, Historia del mueble, tejido, bordado y tapiz (Barcelona: Montaner y Simón, 1897); Rafael Doménech y Luis Pérez Bueno, Muebles antiguos españoles (Barcelona: Bayés, 1921); Joaquín Enríquez, Catálogo de la Exposición de Mobiliario Español de los siglos XV, XVI, y primera mitad del XVII (Madrid: Sociedad española de Amigos del Arte, 1918); Arthur Byne y Mildred Stapley, Spanish interiors and furniture (Nueva York: William Helburn, 1921-1925); Grace Hardendorff Burr, Hispanic furniture with examples in the collection of the Hispanic Society of America (Nueva York: The Hispanic Society of America, 1941).

${ }^{3}$ Para un panorama general sobre las desamortizaciones véase: Francisco Fernández Pardo, Dispersión y destrucción del Patrimonio Artístico Español (Madrid: Fundación Universitaria Española, 2017), Tomo II; y Francisco Javier Campos y Fernández de Sevilla (coord.), La desamortización: El expolio del Patrimonio Artístico y Cultural de la iglesia en España (San Lorenzo del Escorial: ediciones Escurialenses, 2007);

${ }^{4}$ Pedro Martínez Plaza, El coleccionismo de pintura en Madrid durante el siglo XIX (Madrid: Centro de Estudios Europa Hispánica, 2018), 319-329, 484-487, 493-496

${ }^{5}$ Clara Beltrán Catalán y Artur Ramón Navarro, "Algunos apuntes para una historia del anticuariado en Barcelona: 1910-1936," en El reverso de la historia del arte: exposiciones, comercio y coleccionismo (1850-1950), eds. Clara Beltrán Catalán y Esther Alsina Galofré (Gijón: Trea, 2015), 67-115.

${ }^{6}$ Frederic Mares Deulovol, El mundo fascinante del coleccionismo y de las antigüedades. Memorias de la vida de un coleccionista (Barcelona: Instituto de Cultura de Barcelona, 2000).

${ }^{7}$ Tómese como ejemplo las expediciones que algunos miembros de la Junta de Museos de Barcelona realizaron en 1918 en busca de piezas para el Museo de Bellas Artes de la ciudad, aunque muchas acabaron finalmente en el mercado. Véase: María José Boronat i Trill, La política d'adquisicions de la Junta de Museus 1890-1923 (Barcelona: Publicaciones de la Abadía de Montserrat, 1999), 127-154.

${ }^{8}$ María José Martínez Ruiz, "Entre negocios y trapicheos. Anticuarios, marchantes y autoridades eclesiásticas en las primeras décadas del siglo XX: el caso singular de Raimundo Ruiz"; José Miguel Merino de Cáceres, “Arthur Byne: un expoliador de guante blanco," en La dispersión de objetos de arte fuera de España en los siglos XIX y XX, eds. Fernando Pérez Mulet e Inmaculada Socias Batet (Barcelona, Publicaciones y ediciones de la Universidad, 2011); y María José Martínez Ruiz, "Depredadores de Conventos. Comercio de antigüedades en el entorno de las clausuras españolas: Lionel Harris," El reverso de la historia del arte: exposiciones, comercio y coleccionismo (1850-1950), eds. Clara Beltrán Catalán y Esther Alsina Galofré (Gijón: Trea, 2015).

${ }^{9}$ María José Martínez Ruiz, La enajenación del patrimonio en Castilla y León (Valladolid: Junta de Castilla y León, 2008), Tomo II.

${ }^{10}$ Enríquez, Catálogo de la exposición de mobiliario.

${ }^{11}$ Javier Pérez-Flecha González, "La colección de mobiliario de José Weissberger en el Museo Nacional de Artes Decorativas," Res Mobilis: Revista internacional de investigación en mobiliario y objetos decorativos vol. 5, no. 6 (2016), 371-378.

${ }^{12}$ Manuel Gómez Moreno, El arte en España: Guía del Museo del Palacio Nacional (Barcelona: Imprenta de Eugenio Subirana, 1929). 
${ }^{13}$ Las publicaciones de los Byne en: Merino de Cáceres, "Arthur Byne: un expoliador", 269-272.

${ }^{14}$ Dimitra Gkozgkou, "Los Amigos del Arte: ¿Una Sociedad de ambiguos intereses?," en Nuevas contribuciones en torno al mundo del coleccionismo de arte hispánico en los siglos XIX y XX, eds. Inmaculada Socias Batet y Dimitra Gkozgkou (Gijón, Trea, 2013); y María José Martínez Ruiz, "Dime qué expones y te diré qué vendes. El oscuro negocio de las antigüedades bajo el respetable amparo del coleccionismo artístico", en El Arte Hispánico en las exposiciones internacionales, eds. Inmaculada Socias Batet y Dimitra Gkozgkou (Milán, Hugony Editore, 2014).

${ }^{15}$ Como por ejemplo ocurría con algunas de las piezas que José Weissberger envió a América en 1932, véase: Javier Pérez-Flecha González, "Madrid, París, Londres y Nueva York: José Weissberger y el contrabando de tejidos antiguos en 1932," Goya 373, (diciembre 2020): 318.

${ }^{16}$ Richard L. Kagan, The Spanish Craze. America's Fascination with the Hispanic World 17791939 (Lincoln, University of Nebraska Press, 2019), 133-167.

${ }^{17}$ Richard L. Kagan, "The Spanish Turn: The Discovery of Spanish Art in the United States (1887-1920)," en Collecting Spanish Art: Spain's Golden Age and America's Gilded Age, eds. Inge Reist y José Luis Colomer (Madrid, Centro de Estudios Europa Hispánica, 2012), 24.

${ }^{18}$ Richard L. Kagan, "From Noah to Moses: The Genesis of Historical Scholarship on Spain in the United States," en Spain in America: The Origins of Hispanism in the United States, ed. Richard L. Kagan (Chicago, Universidad de Illinois, 2002), 28-48.

${ }^{19}$ Kagan, The Spanish Craze, 170-184.

${ }^{20}$ Como las de Curtis, Stevenson o Caffin

${ }^{21} \mathrm{El}$ estudio más reciente en español es el de: José Miguel Merino de Cáceres y María José Martínez Ruiz, La destrucción del patrimonio artístico español: W. R. Hearst "el gran acaparador"(Madrid, Cátedra, 2012), 276-292.

${ }^{22}$ Merino de Cáceres y Martínez Ruiz, La destrucción del patrimonio artístico español, 333-348.

${ }^{23}$ María José Martínez Ruiz, "Raimundo y Luis Ruiz: pioneros del mercado de antigüedades españolas en EEUU," Berceo, 161, (2011), 49-87.

${ }^{24}$ Javier Pérez-Flecha González, "José Weissberger (1878-1954) y la dispersión del Patrimonio artístico español: una breve aproximación," en Coleccionismo, mecenazgo y mercado artístico en España e Iberoamérica, coords. Antonio Holguera Cabrera y Ester Prieto Ustio (Sevilla, Universidad de Sevilla, 2017), 805-820.

${ }^{25}$ Arthur Byne, Mildred Stapley Byne y Ercole Canessa, Important Medieval and Early Renaissance Works of Art from Spain (Nueva York, American Art Association, 1927); y María José Martínez Ruiz, "Luces y sombras del coleccionismo artístico en las primeras décadas del siglo XX: el Conde de las Almenas," Goya 307-308 (2005), 281-294.

${ }^{26}$ El archivo de la galería en su primera época (1907-1968) se conserva en el Getty Research Institute de Los Angeles (Estados Unidos). En 92 cajas se cuentan aproximadamente 90.820 hojas de inventario de las piezas que fueron compradas y vendidas por aquella. Se conserva también el archivo fotográfico de la gran mayoría de las obras a las que corresponden estas hojas de inventario. Finalmente hay once cajas con los libros de registro y control de las obras de arte, además de cuatro cajas de documentos de gestión de la galería y dos cajas de correspondencia con potenciales clientes. Para el stock de piezas, véase: Getty Research Institute, Special Collection 840027, Serie 1. (GRI, 840027).

${ }^{27}$ Véase respectivamente: GRI, 840027, caja 4, carpeta $3, \mathrm{n}^{\circ}$ stock 5381 ; caja 7 , carpeta $4, \mathrm{n}^{\circ}$ stock 10192 ; caja 5 , carpeta $1, \mathrm{n}^{\circ}$ stock 6193 ; caja 5 , carpeta $3, \mathrm{n}^{\circ}$ stock 6795 ; y caja 25 , carpeta $2, \mathrm{n}^{\mathrm{o}}$ stock 23564 .

${ }^{28}$ Véase respectivamente: GRI, 840027, caja 22, carpeta $1, \mathrm{n}^{\circ}$ stock 20983 ; caja 28 , carpeta $1, \mathrm{n}^{\circ}$ stock 25934 ; caja 30 , carpeta $2, \mathrm{n}^{\circ}$ stock 28139 ; y caja 37 , carpeta $3, \mathrm{n}^{\circ}$ stock 33876 .

${ }^{29}$ Véase respectivamente: GRI, 840027 , caja 4 , carpeta $1, \mathrm{n}^{\circ}$ stock 4692 ; caja 22 , carpeta $3, \mathrm{n}^{\circ}$ stock 21325 ; caja 9 , carpeta $1, \mathrm{n}^{\circ}$ stock 11558 ; ; caja 28 , carpeta $1, \mathrm{n}^{\circ}$ stock 25872 ; y caja 24 , carpeta $4, \mathrm{n}^{\circ}$ stock 23119 . 
${ }^{30}$ Véase respectivamente: GRI, 840027, caja 10 , carpeta $3, \mathrm{n}^{\circ}$ stock 12600 ; caja 10 , carpeta $4, \mathrm{n}^{\circ}$ stock 12830; caja 29, carpeta $3, \mathrm{n}^{\circ}$ stock 27268 ; y caja 31 , carpeta $5, \mathrm{n}^{\circ}$ stock 29466 .

${ }^{31}$ Hay que anotar, que si pensaron en exportar alguna pieza, las leyes y el control de las mismas había mejorado considerablemente con el nuevo régimen político y era más difícil llevarlo a cabo.

${ }^{32}$ Institut Cambó, Epistolario de Francesc Cambó, carpeta José Weissberger, carta 41.

${ }^{33}$ Para las obras de mobiliario, véase respectivamente: GRI, 840027, caja 22, carpeta $2, \mathrm{n}^{\circ}$ stock 21136; caja 14 , carpeta $2, \mathrm{n}^{\circ}$ stock 15160 ; y caja 1 , carpeta $1, \mathrm{n}^{\circ}$ stock 153 .

${ }^{34}$ Museo Franz Mayer, Acervo Documental, FDFM caja 9, carpeta 335, cartas n ${ }^{\circ} 45$ y 48 de los días 11 y 14 de octubre de 1951 de Weissberger a Mayer; y carta ${ }^{\circ} 47$ del 17 de octubre de 1951 de Mayer a Weissberger.

${ }^{35}$ Museo Franz Mayer, Acervo Documental, FDFM, documentos n ${ }^{\circ} 14,18$ y 37 y carta n ${ }^{\circ} 17$ del 14 de agosto de 1951 de Mayer a Weissberger.

${ }^{36}$ Museo Franz Mayer, Acervo Documental, FDFM, cartas nº 136, 137 y 144 de los días 6 y 9 de julio de 1952 y sin fecha de Weissberger a Mayer. 